\title{
Keyhole Approach and Neuroendoscopy for Cerebral Aneurysms
}

\author{
Won-Sang Cho, M.D., Jeong Eun Kim, M.D., Ph.D., ${ }^{1}$ Hyun-Seung Kang, M.D., Ph.D., ${ }^{1}$ Young-Je Son, M.D., ${ }^{2}$ \\ Jae Seung Bang, M.D., ${ }^{3}$ Chang Wan Oh, M.D., Ph.D. ${ }^{3}$ \\ Department of Neurosurgery,' Seoul National University Hospital, Seoul, Korea \\ Department of Neurosurgery, ${ }^{2}$ Seoul National University Boramae Medical Center, Seoul, Korea \\ Department of Neurosurgery, ${ }^{3}$ Seoul National University Bundang Hospital, Seongnam, Korea
}

Treating diseases in the field of neurosurgery has progressed concomitantly with technical advances. Here, as a surgical armamentarium for the treatment of cerebral aneurysms, the history and present status of the keyhole approach and the use of neuroendoscopy are reviewed, including our clinical data. The major significance of keyhole approach is to expose an essential space toward a target, and to minimize brain exposure and retraction. Among several kinds of keyhole approaches, representative keyhole approaches for anterior circulation aneurysms include superciliary and lateral supraorbital, frontolateral, mini-pterional and mini-interhemispheric approaches. Because only a fixed and limited approach angle toward a target is permitted via the keyhole, however, specialized surgical devices and preoperative planning are very important. Neuroendoscopy has helped to widen the indications of keyhole approaches because it can supply illumination and visualization of structures beyond the straight line of microscopic view. In addition, endoscopic indocyanine green fluorescence angiography is useful to detect and correct any compromise of the perforators and parent arteries, and incomplete clipping. The authors think that keyhole approach and neuroendoscopy are just an intermediate step and robotic neurosurgery would be realized in the near future.

Key Words : Cerebral aneurysms · Keyhole · Neuroendoscopy.

\section{INTRODUCTION}

In the field of neurosurgery, newly established treatments have always been preceded by technical advancements. Cerebral aneurysms are representative cerebrovascular diseases. The treatment paradigm of cerebral aneurysms has changed since the introduction of detachable coils for endovascular therapy approximately 20 years ago. To overcome the previous drawbacks of surgical clipping and to improve surgical out- comes, several tools are recently been introduced, and the direction of progress is towards robotic neurosurgery. Among several tools for minimally invasive neurosurgery, the keyhole approach and neuroendoscopy have been the focus since 1990s, owing to technical advancements after a long stagnation from the initial concept and proposed techniques. The authors reviewed the historical, technical, and clinical perspectives of the keyhole approach and neuroendoscopy for the treatment of cerebral aneurysms.

- Received : January 5, 2017 •Revised : January 27, 2017 •Accepted : January 31, 2017

- Address for reprints : Won-Sang Cho, M.D.

Department of Neurosurgery, Seoul National University Hospital, 101 Daehak-ro, Jongno-gu, Seoul 03080, Korea Tel : +82-2-2072-2824, Fax : +82-2-744-8459, E-mail : nsdrcho@gmail.com

This is an Open Access article distributed under the terms of the Creative Commons Attribution Non-Commercial License (http://creativecommons.org/licenses/by-nc/4.0) which permits unrestricted non-commercial use, distribution, and reproduction in any medium, provided the original work is properly cited. 


\section{HISTORICAL PERSPECTIVES OF ENDOSCOPY IN NEUROSURGERY}

The history of endoscopy originated with cystoscopy for bladder diseases, and over the past 200 years, this procedure progressed with stepwise technical advancements and clinical applications ${ }^{10,40)}$. In 1806, Philip Bozzini devised the basic concept of endoscopy consisting of a long tube and external light source. Antonin Jean Desormeaux developed and clinically performed a cystoscopy in 1853 and first coined the term "endoscope”. In 1879, Maximilian Carl-Fredrich Nitze developed the first modern endoscope comprising a series of lenses and a platinum filament lamp at the distal tip.

In the field of neurosurgery, endoscopy was first introduced for the intraventricular visualization of procedure during the 1920s. Victor de l'Espinasse performed the first endoscopic procedure of resection of a choroid plexus using cystoscopy in 1910. William Jason Mixter performed the first endoscopic third ventriculostomy for hydrocephalus in $1923^{22)}$, Tracy Putman adapted the endoscope for electrocauterization in 1934, and John Scarff developed a new system with a mobile cauterizing electrode, irrigation system, fiberoptic illumination, and movable tip in 1935. Although the potential of endoscopy was recognized, the technical completeness was still immature during this period. In addition, the introduction of the shunt system in 1952 and microscopy in the 1960s pushed the endoscopy to the back burner of development.

However, innovative technical advances by some inventors in the 1950s and 1960s, including Harold Hopkins, an English optical physicist, led to the reappearance of endoscopy in the neurosurgical field. Harold Hopkins and Narinder Singh Kapany developed a fiberoptic cable for light transmission from an external light source in 1950, and Harold Hopkins and Karl Storz invented a rigid high-resolution endoscope with new type of lens in $1966^{40)}$. Following another outstanding development in 1969 by George Smith and Willard Boyle at Bell's laboratory of a charge-coupled device that converts optical data to electrical impulses, endoscopic systems became more compact and effective ${ }^{2)}$. A few clinical applications were reported by Werner Prott for the visualization of the cerebellopontine angle in $1974^{31}$, by Michael Apuzzo for the inspection of basilar bifurcation aneurysm, lumbar discectomy and trans-sphenoidal approach in $1977^{1)}$, and by Falk Oppel for microvascular decompression in $1981^{26)}$.
Due to the progressive improvement of endoscopy systems and surgical instruments in the 1970s, neuroendoscopy has become comparable or even superior to microscopy in selected cases since the $1990 \mathrm{~s}^{10,40)}$. Generally, neuroendoscopy is commonly used for intraventricular, skull base, spinal, and other lesions. Intraventricular lesions, such as hydrocephalus, cysts and tumours, have been the major target of endoscopic procedures from the beginning. Endoscopic approaches have made the aggressive skull base approaches less invasive and safer. The endoscopic endonasal approach is the representative approach targeting benign tumours such as pituitary adenoma, craniopharyngioma, chordoma and meningioma, and, recently, cerebral aneurysms. In spine diseases, endoscopy is used for thoracoscopic sympathectomy, discectomy, laminotomy, and resection of tumours and cysts. For paediatric cases, neuroendoscopy has been applied for hydrocephalus, intraventricular cysts and tumours, skull base tumours, and, recently, craniosynostosis. Cerebrovascular diseases are considered the final target of neuroendoscopy because bleeding hinders the endoscopic view, and controlling the bleeding is difficult under an endoscopic view with limited instruments. However, the indications are slowly increasing with the introduction of new endoscopic instruments as well as exoscopy. Certain vascular lesions at specific locations (e.g., posterior circulation aneurysms) could be treated more effectively with an endoscopic approach.

\section{ENDOSCOPIC KEYHOLE APPROACH FOR CERE- BRAL ANEURYSMS}

\section{Keyhole approach}

Looking back on the history of cerebral aneurysm treatment, surgical managements have improved since Victor Horsley's ligation of the common carotid artery for an ipsilateral cerebral aneurysm in 1855 . Normann Dott first wrapped a cerebral aneurysm in $1933^{11)}$. Walter Dandy performed the first direct neck clipping with a V-shaped silver clip in $1935^{8)}$, and Gazi Yasargil started to use microscopy in the $1960 \mathrm{~s}^{20)}$. The era of endovascular treatment began when Guido Guglielmi invented detachable coils in 1991 ${ }^{17)}$, and endovascular intervention is accepted as a primary treatment modality for cerebral aneurysms with lower complication rates and satisfactory outcomes compared to surgical clipping ${ }^{23)}$, To reduce 
surgical morbidities, much effort has been recently made, such as intraoperative cerebral angiography, intraoperative indocyanine green (ICG) angiography, intraoperative physiologic monitoring, neuroendoscopy, the keyhole approach, and new instrument designs.

The keyhole approach is not so long that Donald Wilson and Mario Brock first attempted a limited craniotomy as a premature step in $1970 \mathrm{~s}^{3,37)}$, and John Jane described a modified supraorbital approach with minimal brain retraction in $1982^{19)}$. Coming into the late 1980s, the concept and indications of a keyhole approach were established by Josip Paladino and Axel Perneczky ${ }^{2730,36)}$. A standard craniotomy supplies a sufficient space for inspection and instruments as well as room for diverse angles of approach towards the target lesion. Meanwhile, a keyhole craniotomy provides an essential space for microscopic viewing and 2 or 3 instruments. A wide range of areas can be approached by varying the microscopic angle of the view; however, only a fixed and limited approach angle towards one target is permitted via the keyhole. According to the Axel Perneczky's report in $1998^{36}$, the keyhole approach is not limited via a limited corridor but is rather a tailored and adjusted method for minimal exposure and retraction of the brain. Its advantages include minimal brain exposure, excellent cosmetic results, preservation of the surrounding structures, and short procedural time. It also has some disadvantages: less opportunity for changing a plan, weak microscopic illumination, and difficulty in proximal control over the parent arteries. However, these types of disadvantages can be overcome via preoperative planning with imaging modalities, intraoperative manipulation with instruments such as an endoscope and specific devices, and specific facilities such as a hybrid operating system ${ }^{9)}$. Keyhole approaches may be still inappropriate in cases with a high probability of massive bleeding and brain swelling; however, the proportion of keyhole surgeries appears to be increasing.

Keyhole approaches include supraorbital, subtemporal, suboccipital, interhemispheric, and transcortical ${ }^{30)}$. The symbolic and representative approach is supraorbital, which is applicable for most anterior circulation aneurysms. A supraorbital keyhole craniotomy exposes the anterior cranial fossa just above the orbit and sphenoid ridge (Fig. 1). It can be classified into 3 types: (1) superciliary (or eyebrow) supraorbital craniotomy (SSO approach) $)^{6,28,36)}$; (2) frontolateral supraorbital craniotomy (FL approach) ${ }^{3,38)}$; and (3) lateral supraorbital craniotomy (LSO approach) ${ }^{5,18)}$. When performing the SSO approach, surgeons should consider surrounding structures: supraorbital and supratrochlear nerves at the medial side of the incision, the frontal branch of the facial nerve at the lateral side, and the extent of the frontal sinus. Muscle injury and bleeding are minimal because peeling the temporalis muscle to make the keyhole is sufficient and does not destroy the sphenoid ridge. However, a small craniotomy sometimes makes it hard to retract the frontal lobe and secure a sufficient space for the procedure, forehead hypaesthesia and frontalis palsy temporarily but infrequently occur, and olfactory nerve injury during clipping of the anterior communicating artery (ACoA) aneurysms is not rare. The FL approach is fundamentally the same as the SSO approach; however, FL approach has a lower risk of nerve injury, a higher cosmetic satisfaction and a chance to make a larger bone flap because the skin incision is made just behind the hairline and an interfacial dissection is performed. The LSO approach includes a skin incision just behind the hair-
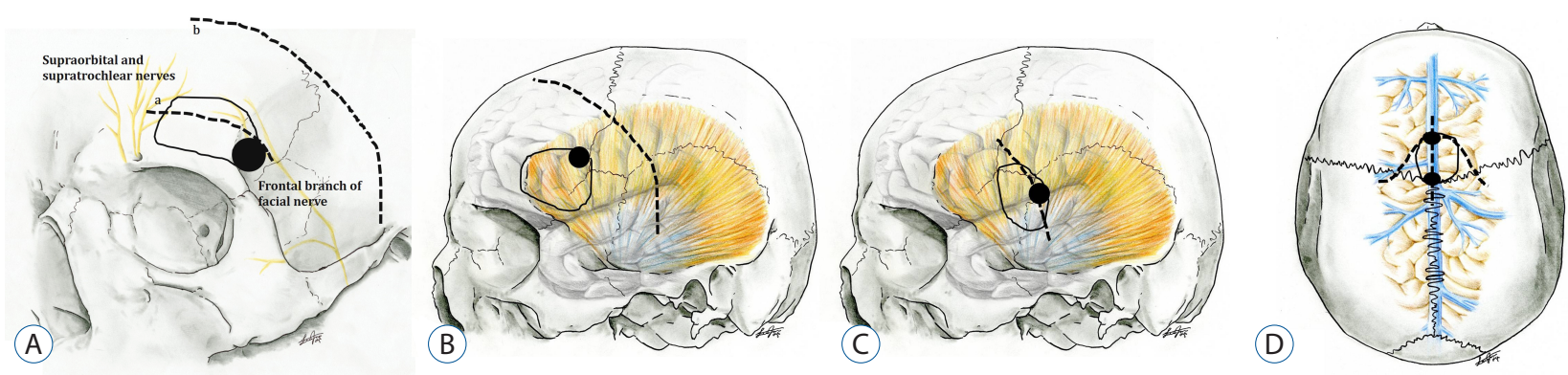

Fig. 1. Illustrations of various types of keyhole craniotomy. A : Superciliary supraorbital (a, skin incision at the upper margin of eyebrow) and frontolateral ( $b$, skin incision just behind the hairline) keyhole craniotomy. $B$ : Lateral supraorbital craniotomy above the sphenoid ridge, detaching the temporalis muscle. C : mini-pterional keyhole craniotomy exposing the perisylvian area. D : Mini-interhemispheric keyhole craniotomy after linear midline or inverted bowl-shaped skin incisions. Dotted lines indicate the skin incision, black circles indicate the keyhole and solid lines indicate the margin of craniotomy in a size of about $3-4 \mathrm{~cm}$ at each plane. 
line, incision and retraction of the temporalis muscle, and a more laterally located supraorbital craniotomy. Therefore, there exists a risk of muscle problems such as pain, bleeding, swelling and atrophy. However, it is advantageous in cases with inferiorly directed aneurysms and large frontal sinus, and it has a lower risk of olfactory nerve injury. If necessary, the craniotomy can be extended into the middle cranial fossa crossing the sphenoid ridge such that the LSO approach has a wider range of application through medial and lateral sylvian dissection; compared to the SSO and FL approaches, the medial sylvian dissection is the only window towards the aneurysms. Meanwhile, in cases with intradural bony drilling of sphenoid ridge and anterior clinoid process, endoscopic assistance, and bilateral approach via the unilateral corridor, LSO and FL approaches are more advantageous than SSO approach because of the flexibility of craniotomy size. Finally, there are mini-pterional (MP) and mini-interhemispheric (MI) approaches. The MP approach is mainly used for middle cerebral artery aneurysms by focally exposing the perisylvian $\operatorname{area}^{24,34)}$. Via the MI approach, aneurysms at the distal anterior cerebral arteries and ACoAs can be clipped ${ }^{30)}$. The most important aspect in selecting MP and MI approaches is the venous structures because damage to major bridging veins can result in painful complications of venous infarction and haemorrhagic conversion. Thus, preoperative imaging of both the arteries and veins is essential to select an appropriate approach and determine a craniotomy area.

Based on the personal experience during the past 3 years, 377 aneurysms in 280 patients were treated via keyhole approaches and composed $87.9 \%$ of all the aneurysms treated. The percentage of patients undergoing the FL, LSO, SSO, MP and MI approaches were $43.8 \%, 23.8 \%, 15.5 \%, 13.4 \%$, and $3.5 \%$, respectively; and the treatment results consisted of complete occlusion in $75.4 \%$ of aneurysms, residual neck (remnant $<1 \mathrm{~mm}$ ) in $20.7 \%$, and residual sac in $4.8 \%$. Among 325 unruptured aneurysms in 244 patients, the mortality was zero, and the permanent morbidity was $0.6 \%$ per aneurysm and $0.8 \%$ per patient with excellent cosmetic results and a short operation time of approximately 150 minutes. Occasionally, an endoscope and mirror were needed because of weak illumination and blind spots beyond the line of the microscopic view, and specific instruments such as devices with tubular shaped and bayonet type of shafts, various designs of aneurysm clips and malleable clip applier with a small head were effective.

\section{Roles of endoscopy}

Modern neuroendoscopy has some advantages over microscopy—strong illumination, clear depiction in a close-up view and a wide viewing angle. In addition, when using the holding arms, bimanual manipulation is possible ${ }^{14,29)}$, which allows surgeons to safely and precisely clip certain aneurysms beyond the straight line of the microscopic view ${ }^{39)}$. This usefulness can be highlighted when clipping is performed via the small corridor of keyhole approaches. Sometimes, a micromirror is simple to use; however, the image resolution is low, and fog on the mirror can be problematic. Neuroendoscopy was implemented to treat aneurysms in the early 1990s, and its role has become widespread from assisting microscopy procedures to providing the main view. In selected cases, aneurysm clipping has evolved from endoscope-assisted procedures to endoscope-controlled ones ${ }^{1,14)}$, and neuroendoscopy is progressively used via the keyhole ${ }^{13,33)}$ and endonasal ${ }^{12,15,16,35)}$ approaches as well as conventional approaches. Endoscopic endonasal approaches are thought to be a good alternative for aneurysms located in the medial paraclinoid segment of the internal carotid artery (ICA) and posterior circulations such as basilar bifurcation, as well as those in cerebellar and vertebral arteries, which are limited with conventional surgical approaches ${ }^{35}$. To date, the smallest endoscope diameter is $2.7 \mathrm{~mm}$, and a rigid endoscope produces the best imaging quality. Neuroendoscopy with softer (fiberoptic and steerable) shafts that have a smaller diameter would be more useful in the near future.

Personally, the author started to use neuroendoscopy after a painful experience during an incomplete inspection around the aneurysm and blind clipping using a keyhole approach. Neuroendoscopy is mainly used in selected cases such as inferiorly directed aneurysms at the distal ICA, superoposteriorly directed aneurysms at the ACoA and middle cerebral arteries, and ICA bifurcations. In total, 9.0\% (34 of 377 aneurysms) were clipped using either endoscopic-assisted or controlled keyhole approaches.

\section{Endoscopic ICG fluorescence angiography}

ICG fluorescence angiography (ICGA) is a prominent techniques in the surgical treatment of cerebrovascular diseases. Since Raabe et al. introduced this technique to the field of cerebrovascular surgery in $2003^{32}$, microscopic ICGA has been widely used in aneurysm clipping, bypass surgery, arte- 
riovenous fistulas and malformations in the brain and spine. It is especially used in aneurysm surgeries in order to detect and correct any compromise of the perforators and parent arteries and/or incomplete clipping. However, microscopic ICGA systems have some shortcomings for structures beyond the line of the microscopic view and deep-seated structures with weak illumination. Such limitations can be profound during the procedures utilizing the keyhole craniotomy. Therefore, some neurosurgeons from Japan, Germany and Korea (our system) developed endoscopic ICG angiography (eICGA) systems ${ }^{4,7,21,25)}$. Compared to conventional endoscopy, endoscopic ICGA has some additional advantages for aneurysm clipping in that it can visualize the ICG fluorescence within small perforators, parent arteries and clipped aneurysms beyond the line of microscopic view, detect even faint fluorescence of deep-seated structures, and obtain ICG fluorescent images for a longer duration. Our system has a unique technical superiority over the commercial endoscopic ICGA systems - simultaneous display and real-time merging of both visible light and ICG fluorescence images. Previous systems can alternatively visualize either the visible light or ICG fluorescence images, which is inconvenient and has the risk of violating unseen structures during the fluorescence mode. Recently, we completed a prospective clinical study with our dual channel eICGA system in treating cerebral aneurysms. Our system showed a higher detection rate of branch orifices and the exact clip position than the commercial microscopic ICGA (Fig. 2).

\section{CONCLUSION}

With the advent of new and advanced surgical instruments and techniques, the percentage of aneurysm clippings utilizing a keyhole approach is increasing. Neuroendoscopy also has progressively become more useful for either keyhole or
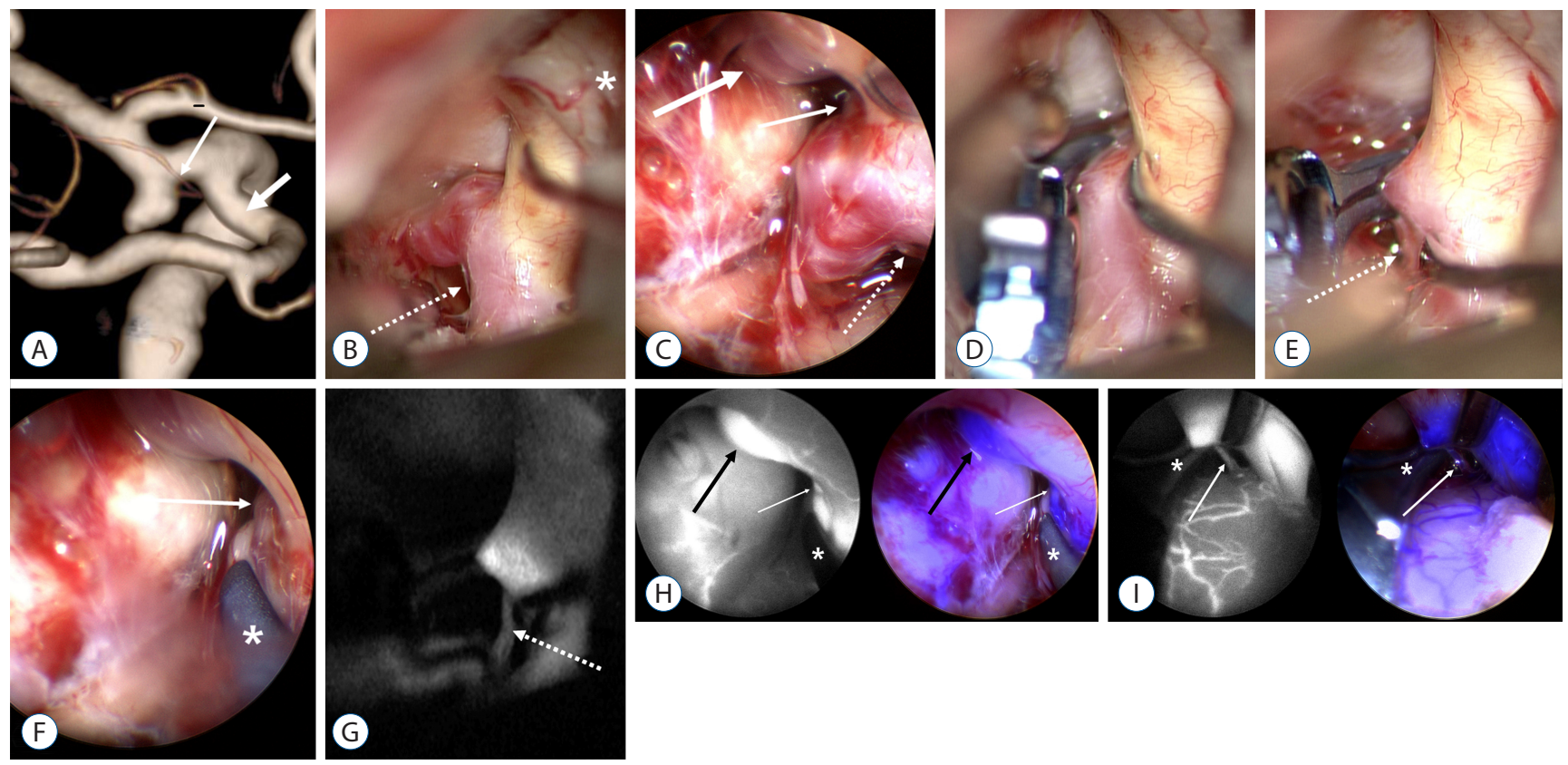

Fig. 2. A case of left anterior choroidal artery $(A C h A)$ aneurysm clipped via lateral supraorbital approach with dual channel endoscopic indocyanine green fluorescence angiography (ICGA). A : Aneurysm, AChA (thin arrow) and posterior communicating artery (PCoA, thick arrow) are seen on right lateral projection of 3D reconstructed angiography. B : AChA is not identified even retracting the internal carotid artery (asterisk: left optic nerve). However, a small perforator which seems posterior branch of AChA unseen on preoperative angiography (dotted arrow) is arising from the posterior neck of aneurysm. C : On endoscopic view, the orifices of PCoA (thick arrow), anterior (thin arrow) and posterior branches of AChA (dotted arrow) are shown. D and E : On microscopy, anterior branch of AChA is not seen even after clipping the aneurysm, however, posterior branch of AChA (dotted arrow) is demonstrated. F : On endoscopy, the orifice of anterior branch of AChA (arrow) and tip of clip blade (asterisk) are well identified. G : On microscopic ICGA in the same viewpoint of E, posterior branch of AChA (dotted arrow) is seen. $\mathrm{H}$ : On dual channel endoscopic ICGA of ICG image (left) and merging image (right), ICG fluorescence is visualized at the orifices of PCOA (thick black arrows) and anterior branch of AChA (thin white arrows), however not within the aneurysm (asterisk: clip blade). I : On dual channel endoscopic ICGA, ICG fluorescence is shown in posterior branch of AChA (arrow) above the clip blade (asterisk). 
endonasal approaches for cerebral aneurysms. Developments in minimally invasive surgical approaches and neuroendoscopy such as 3D display and exoscopy are considered an intermediate step towards robotic neurosurgery, which would be the pinnacle of achieving minimal invasiveness and complication risks. In the near future, the authors predict the use of tele-surgery, microanastomosis with a haptic sense, and intraoperative imaging of the anatomy, physiology and pathology of patients with robotic systems. A step towards robotic surgery has already begun in the field of general and urologic surgery, and neurosurgery would be the final frontier.

\section{- Acknowledgements}

The authors thanked to Dr. Jae Meen Lee for medical illustration.

\section{References}

1. Apuzzo ML, Heifetz MD, Weiss MH, Kurze $T$ : Neurosurgical endoscopy using the side-viewing telescope. J Neurosurg 46 : 398-400, 1977

2. Boyle WS, Smith GE : The inception of charge-coupled devices. IEEE Transact Elect Dev 23 : 661-663, 1976

3. Brock M, Dietz $\mathrm{H}$ : The small frontolateral approach for the microsurgical treatment of intracranial aneurysms. Neurochirurgia Acta (Stuttg) 21 : 185-191, 1978

4. Bruneau M, Appelboom G, Rynkowski M, Van Cutsem N, Mine B, De Witte 0 : Endoscope-integrated ICG technology : first application during intracranial aneurysm surgery. Neurosurg Rev 36 : 77-84; discussion 84-85, 2013

5. Cha KC, Hong SC, Kim JS : Comparison between lateral supraorbital approach and pterional approach in the surgical treatment of unruptured intracranial aneurysm. J Korean Neurosurg Soc 51 : 334-337, 2012

6. Chalouhi N, Jabbour P, Ibrahim I, Starke RM, Younes P, El Hage G, et al. : Surgical treatment of ruptured anterior circulation aneurysms: comparison of pterional and supraorbital keyhole approaches. Neurosurgery 72 : 437-441; discussion 441-442, 2013

7. Cho WS, Kim JE, Kim SH, Kim HC, Kang U, Lee DS : Endoscopic fluorescence angiography with indocyanine green: a preclinical study in the swine. J Korean Neurosurg Soc 58 : 513-517, 2015

8. Dandy WE : Intracranial aneurysms of the internal carotid artery: cured by operation. Ann Surg $107:$ 654-659, 1938

9. Davies JM, Lawton MT : Advances in open microsurgery for cerebral aneurysms. Neurosurgery 74 Suppl 1 : S7-S16, 2014

10. Di leva A, Tam M, Tschabitscher M, Cusimano MD : A journey into the technical evolution of neuroendoscopy. World Neurosurg 82 : e777e789, 2014

11. Dott NM : Intracranial aneurysms cerebral arterio-radiography and surgi- cal treatment. Edinb Med J 40 : 219-234, 1933

12. Enseñat J, Alobid I, de Notaris M, Sanchez M, Valero R, Prats-Galino A, et al. : Endoscopic endonasal clipping of a ruptured vertebral-posterior inferior cerebellar artery aneurysm: technical case report. Neurosurgery 69(1 Suppl Operative) : oneE121-oneE127; discussion oneE121oneE127, 2011

13. Fischer G, Oertel J, Perneczky A : Endoscopy in aneurysm surgery. Neurosurgery 70(2 Suppl Operative) : 184-190; discussion 190-191, 2012

14. Fries $G$, Perneczky A : Endoscope-assisted brain surgery: part 2--analysis of 380 procedures. Neurosurgery $42: 226-231$; discussion 231-232, 1998

15. Froelich S, Cebula H, Debry C, Boyer P : Anterior communicating artery aneurysm clipped via an endoscopic endonasal approach: technical note. Neurosurgery 68(2 Suppl Operative) : 310-316; discussion 315-316, 2011

16. Germanwala AV, Zanation AM : Endoscopic endonasal approach for clipping of ruptured and unruptured paraclinoid cerebral aneurysms: case report. Neurosurgery 68(1 Suppl Operative) : 234-239; discussion 240, 2011

17. Guglielmi G, Viñuela F, Dion J, Duckwiler G : Electrothrombosis of saccular aneurysms via endovascular approach. Part 2: Preliminary clinical experience. J Neurosurg $75: 8-14,1991$

18. Hernesniemi J, Ishii K, Niemelä M, Smrcka M, Kivipelto L, Fujiki M, et al. : Lateral supraorbital approach as an alternative to the classical pterional approach. Acta Neurochir Suppl 94 : 17-21, 2005

19. Jane JA, Park TS, Pobereskin $L H$, Winn HR, Butler AB : The supraorbital approach: technical note. Neurosurgery $11:$ 537-542, 1982

20. Krayenbühl HA, Yaşargil MG, Flamm ES, Tew JM Jr : Microsurgical treatment of intracranial saccular aneurysms. J Neurosurg 37 : 678-686, 1972

21. Mielke D, Malinova V, Rohde V : Comparison of intraoperative microscopic and endoscopic ICG angiography in aneurysm surgery. Neurosurgery 10 Suppl 3 : 418-425; discussion 425, 2014

22. Mixter WJ : Ventriculoscopy and puncture of floor of third ventriclepreliminary report of a case. Boston Med Surg J 188 : 277-278, 1923

23. Molyneux A, Kerr R, Stratton I, Sandercock P, Clarke M, Shrimpton J, Holman R; International Subarachnoid Aneurysm Trial (ISAT) Collaborative Group : International Subarachnoid Aneurysm Trial (ISAT) of neurosurgical clipping versus endovascular coiling in 2143 patients with ruptured intracranial aneurysms: a randomised trial. Lancet 360 : 1267-1274, 2002

24. Nathal E, Gomez-Amador JL : Anatomic and surgical basis of the sphenoid ridge keyhole approach for cerebral aneurysms. Neurosurgery 56(1 Suppl) : 178-185; discussion 178-185, 2005

25. Nishiyama Y, Kinouchi H, Senbokuya N, Kato T, Kanemaru K, Yoshioka $H$, et al. : Endoscopic indocyanine green video angiography in aneurysm surgery: an innovative method for intraoperative assessment of blood flow in vasculature hidden from microscopic view. J Neurosurg 117 : 302-308, 2012

26. Oppel F, Mulch G, Brock M : Endoscopic section of the sensory trigemi- 
nal root, the glossopharyngeal nerve, and the cranial part of the vagus for intractable facial pain caused by upper jaw carcinoma. Surg Neurol 16 : 92-95, 1981

27. Paladino J, Pirker N, Stimac D, Stern-Padovan R : Eyebrow keyhole approach in vascular neurosurgery. Minim Invasive Neurosurg 41 : 200-203, 1998

28. Park J, Woo H, Kang DH, Sung JK, Kim Y. Superciliary keyhole approach for small unruptured aneurysms in anterior cerebral circulation. Neurosurgery 68(2 Suppl Operative) : 300-309; discussion 309, 2011

29. Perneczky A, Fries G : Endoscope-assisted brain surgery: part 1-evolution, basic concept, and current technique. Neurosurgery 42 : 219 224; discussion 224-225, 1998

30. Perneczky A, MullerForell W, Lindert E, Fries G : Current strategies in keyhole and endoscope assisted microneurosurgery in Perneczky A (ed) : Keyhole Concept in Neurosurgery. Stuttgart : Thieme Medical Publishers, 1999, p3751

31. Prott W: Cisternoscopy of the cerebellopontine angle (author's transl). HNO 22 : 337-341, 1974

32. Raabe A, Beck J, Gerlach R, Zimmermann M, Seifert V : Near-infrared indocyanine green video angiography: a new method for intraoperative assessment of vascular flow. Neurosurgery 52 : 132-139; discussion 139, 2003

33. Reisch R, Fischer G, Stadie A, Kockro R, Cesnulis E, Hopf N : The supra- orbital endoscopic approach for aneurysms. World Neurosurg 82(6 Suppl) : S130-S137, 2014

34. Son YJ, Han DH, Kim JE : Image-guided surgery for treatment of unruptured middle cerebral artery aneurysms. Neurosurgery 61(5 Suppl 2) : 266-271; discussion 271-272, 2007

35. Szentirmai $O$, Hong Y, Mascarenhas L, Salek AA, Stieg PE, Anand VK, et al. : Endoscopic endonasal clip ligation of cerebral aneurysms: an anatomical feasibility study and future directions. J Neurosurg 124 : 463 468, 2016

36. van Lindert E, Perneczky A, Fries G. Pierangeli E : The supraorbital keyhole approach to supratentorial aneurysms: concept and technique. Surg Neurol 49 : 481-489; discussion 489-490, 1998

37. Wilson DH : Limited exposure in cerebral surgery. Technical note. J Neurosurg 34 : 102-106, 1971

38. Yang J, Oh CW, Kwon OK, Hwang G, Kim T, Moon JU, et al. : The usefulness of the frontolateral approach as a minimally invasive corridor for clipping of anterior circulation aneurysm. J Cerebrovasc Endovasc Neurosurg $16: 235-240,2014$

39. Yoshioka $H$, Kinouchi $H$ : The roles of endoscope in aneurysmal surgery. Neurol Med Chir (Tokyo) 55 : 469-478, 2015

40. Zada G, Liu C, Apuzzo ML : "Through the looking glass": optical physics, issues, and the evolution of neuroendoscopy. World Neurosurg 77 : 92-102, 2012 